\title{
Multimodality imaging for the prevention of cardiovascular events: Coronary artery calcium and beyond
}

\author{
Duygu Kocyigit ${ }^{1}$, Alexandra Scanameo ${ }^{2}, \mathrm{Bo} \mathrm{Xu}^{1}$ \\ ${ }^{1}$ Section of Cardiovascular Imaging, Robert and Suzanne Tomsich Department of Cardiovascular Medicine, Sydell and Arnold Miller Family Heart \\ and Vascular Institute, Cleveland Clinic, Cleveland, OH, USA; ${ }^{2}$ Drexel University College of Medicine, Philadelphia, PA, USA \\ Contributions: (I) Conception and design: All authors; (II) Administrative support: None; (III) Provision of study material or patients: None; (IV) \\ Collection and assembly of data: D Kocyigit, B Xu; (V) Data analysis and interpretation: All authors; (VI) Manuscript writing: All authors; (VII) Final \\ approval of manuscript: All authors. \\ Correspondence to: Bo Xu, MD, FACC, FRACP, FASE. Section of Cardiovascular Imaging, Robert and Suzanne Tomsich Department of \\ Cardiovascular Medicine, Sydell and Arnold Miller Family Heart and Vascular Institute, Cleveland Clinic, 9500 Euclid Avenue, Desk J1-5, \\ Cleveland, OH 44195, USA. Email: xub@ccf.org.
}

\begin{abstract}
Atherosclerotic cardiovascular disease (ASCVD) has been the leading cause of death worldwide for more than a decade. Prevention is of utmost importance to reduce related mortality. The innovations in cardiovascular imaging technology, in addition to our improved understanding of coronary atherosclerosis pathogenesis, have resulted in cardiovascular imaging becoming one of the most influential tools for diagnosis and risk stratification in ASCVD. Although numerous publications have emerged on this topic, data that guide routine cardiology clinical practice currently focus on the utility of a limited number of such modalities, namely arterial ultrasonography and computed tomography. Herein, current evidence with respect to the role of multimodality cardiovascular imaging on ASCVD prevention will be reviewed.
\end{abstract}

Keywords: Multimodality cardiovascular imaging; atherosclerotic cardiovascular disease (ASCVD); prevention; ultrasonography; computed tomography; coronary artery calcium score; magnetic resonance imaging; positron emission tomography

Submitted Nov 29, 2019. Accepted for publication Jan 15, 2020.

doi: $10.21037 / \mathrm{cdt}-19-654$

View this article at: http://dx.doi.org/10.21037/cdt-19-654

\section{Introduction}

Atherosclerosis is a chronic progressive inflammatory disease that is characterized with fibrous and/or fatty lesion formation in the intimal layer of the arterial wall (1). Although atherogenesis may emerge in any arterial bed, epidemiological data suggest that involvement of the coronary arterial bed by atherogenesis (namely, ischemic heart disease) is the leading cause of mortality worldwide (2).

The concept of "precision medicine" has led to a shift from "population" to a more "personalized" approach (3). When predicted 5-year atherosclerotic cardiovascular disease (ASCVD) risk and observed ASCVD risk were compared in a large-scale study involving 307,591 adults, ASCVD risk score was shown to overestimate cardiovascular
(CV) risk in the overall adult population without diabetes, as well as in the sex, ethnic and socioeconomic status subgroups (4), emphasizing the need for additional data in fine tuning of risk estimation. Imaging is one of the tools that can help elucidate the "proof of disease" and therefore, is an essential component of ASCVD prevention.

Imaging for prevention of ASCVD has three main functions: (I) diagnosis of the disease based on arterial wall imaging (in terms of both primary and secondary prevention), (II) ASCVD risk stratification based on multi-level imaging (in terms of both primary and secondary prevention), (III) targeted treatment of atherosclerotic plaques (in terms of secondary prevention). Therefore, imaging has the potential to provide evidence that may guide clinical therapeutic decisions and motivate patient behavior. 
This review focuses on the utility of $\mathrm{CV}$ imaging for ASCVD prevention with regards to diagnosis and risk stratification. The term coronary artery disease (CAD) is used to define the characteristics of the study population (to demonstrate whether it is a primary or secondary prevention cohort) and the endpoints (such as incident CAD, mortality due to CAD etc.) of the studies presented in this review.

\section{Arterial ultrasonography}

Ultrasonography is a traditional imaging modality, yet it may provide clinical diagnostic and prognostic information of utmost importance. Non-invasive ultrasonography of the main arteries (carotid and femoral arteries), as well as invasive intravascular ultrasound (IVUS) of the coronary arteries in diagnosing atherosclerosis, risk stratification and prognosis assessment will be reviewed here.

\section{Carotid artery ultrasonography}

Carotid artery ultrasound enables assessment of: (I) plaque presence, (II) plaque burden, (III) plaque texture, (IV) plaque ulcer volume, (V) intima-media thickness (IMT).

\section{Plaque presence}

A substudy of the Atherosclerosis Risk in Communities (ARIC) study (5) ( $\mathrm{n}=13,145$, individuals with CAD or stroke were excluded from the initial study cohort) showed that carotid plaque presence/absence when added to traditional risk factors (TRFs) had a better performance than TRFs alone for predicting incident CAD events defined as myocardial infarction (MI), coronary revascularization or definite CAD death (5). The area under the curve (AUC) improved to 0.751 (95\% CI for the difference in adjusted AUC: $0.006-0.013$ ) from 0.742 with the addition of plaque presence/absence; this improvement was more pronounced in females (AUC: $0.770,95 \%$ CI for the difference in adjusted AUC: 0.005-0.016) than in men (AUC: 0.686, 95\% CI for the difference in adjusted AUC: 0.005-0.017). Carotid plaque presence/absence added to TRFs had a better net reclassification index (NRI) compared to TRFs alone (7.7\%, 95\% CI: 2.3-11.4) (5). Clinical NRI, defined as NRI in the intermediate-risk group, was even higher (17.7\%, 95\% CI: 10.9-24.7) when carotid plaque presence/ absence was added in addition to TRFs (5).

\section{Plaque burden}

Plaque burden assessment in the carotid arteries may be made through carotid plaque area measurement in the longitudinal plane and carotid plaque volume measurement.

A study investigated the impact of baseline carotid plaque area on the composite endpoint of MI, stroke and vascular death in 1686 patients followed up at a prevention clinic for a mean duration of 2.5 years (6). Five-year risk of composite endpoint was increased with increasing plaque area quartiles (Q) after adjusting for baseline patient characteristics (RR: 3.5, 95\% CI: $1.8-6.7, \mathrm{P}<0.001$ in Q4; RR: 2.5 , 95\% CI: 1.4-4.4, $\mathrm{P}=0.001$ in $\mathrm{Q} 3$; RR: $1.9,95 \%$ CI: $1.1-3.3, \mathrm{P}=0.2$ in Q2) (6). 1,085 patients had serial follow-up imaging for carotid plaque area. Patients with plaque progression were more likely to experience the composite endpoint than those with no change in plaque area (RR: $2.1,95 \% \mathrm{CI}$ : $1.2-3.6, \mathrm{P}=0.005)(6)$.

Follow-up of the imaging study group of the Biolmage Study (A Clinical Study of Burden of Atherosclerotic Disease in an At-Risk Population) (7) ( $\mathrm{n}=5,808$ asymptomatic adults) for a median duration of 2.7 years showed that increase in carotid plaque burden was associated with higher cumulative incidence of primary (MI, $\mathrm{CV}$ death and ischemic stroke) and secondary (unstable angina, coronary revascularization and all-cause death) major adverse cardiac events (MACE) after adjustment for TRFs (7). The hazard ratios (HR) of increasing tertiles of carotid plaque burden were 0.78 (95\% CI: 0.31-1.91), 1.45 (95\% CI: 0.67-3.14) and 2.36 (95\% CI: 1.13-4.92), respectively for primary MACE $(\mathrm{P}=0.03)(7)$. For secondary MACE, HRs of increasing tertiles of carotid plaque burden were 1.11 (95\% CI: 0.49-2.53), 1.58 (95\% CI: 0.74-3.38) and 2.99 (95\% CI: 1.48-6.05), respectively $(\mathrm{P}=0.01)(7)$. Significant improvement in NRI was observed with addition of carotid plaque burden on top of TRFs for prediction of both primary $(0.23 \%, 95 \%$ CI: $0.05-0.31)$ and secondary (0.17\%, 95\% CI: 0.11-0.26) MACE endpoints (7).

Carotid plaque burden assessment using plaque area measurements were then followed with studies highlighting the three-dimensional (3D) volumetric quantification of plaque burden. In The High Risk Plaque BioImage study that examined 6,101 asymptomatic subjects (the imaging study group) (8), when adjusted for TRFs, carotid plaque volume was the imaging modality that had the most strong association with coronary artery calcium score (CACS) (OR for the highest tertile of carotid plaque volume: 4.79 , $95 \%$ CI: 4.11-5.57, $\mathrm{P}<0.0001)$ among other imaging modalities, including carotid IMT and abdominal aortic diameter (8).

Progression in carotid plaque volume was suggested to predict adverse outcomes defined as MI, transient ischemic 
Table 1 The utility of non-invasive arterial ultrasonography for ASCVD prevention with regards to diagnosis and risk stratification

\begin{tabular}{|c|c|}
\hline Guidelines & Recommendations \\
\hline $\begin{array}{l}2019 \text { ESC/EAS Guidelines for the } \\
\text { management of dyslipidemias (10)- }\end{array}$ & $\begin{array}{l}\text { Significant plaque on carotid ultrasound is accepted as evidence for ASCVD and places the } \\
\text { patient in the very high CV risk group }\end{array}$ \\
\hline $\begin{array}{l}2019 \text { ESC/EAS Guidelines for the } \\
\text { management of dyslipidemias (10) }\end{array}$ & $\begin{array}{l}\text { Carotid artery plaque burden, regardless of the measurement technique (area or volume), } \\
\text { can be useful as a risk modifier in subjects with low and moderate CV risk (Class: lla, LOE: B) }\end{array}$ \\
\hline $\begin{array}{l}2016 \text { ESC guidelines on CVD prevention in } \\
\text { clinical practice (11)- }\end{array}$ & Carotid IMT measurement is not recommended for risk stratification (Class: III, LOE: A) \\
\hline $\begin{array}{l}2013 \text { ACCF/AHA guidelines on the } \\
\text { assessment of CV risk (12) }\end{array}$ & Carotid IMT measurement is not recommended for risk stratification (Class: III, LOE: B) \\
\hline
\end{tabular}

attack (TIA), stroke and vascular death in a study that included patients with baseline total carotid plaque area: 40$600 \mathrm{~m}^{2}(\mathrm{n}=349)$ who were followed-up at a prevention clinic (median: 3.17 years) (9). Progression in total plaque volume, but not total plaque area, was an independent predictor of any adverse event after adjusting for TRFs $(\mathrm{P}=0.001)$ (9).

The utility of carotid artery plaque burden assessment for ASCVD prevention with regards to diagnosis and risk stratification based on European guidelines is outlined in Table 1. In the American guidelines, there is no recommendation with respect to carotid artery plaque burden assessment for the purpose of ASCVD risk stratification. Only data regarding carotid artery plaque assessment in the prevention of atherosclerotic disease comes from 2010 AHA (American Heart Association)/ ASA (American Stroke Association) guidelines for the primary prevention of stroke (13), which states that screening for asymptomatic carotid artery stenosis is not indicated (Class: III, LOE: B). 2011 ASA/ACCF (American College of Cardiology Foundation)/AHA guidelines on the management of patients with extracranial carotid and vertebral artery disease (14) also does not recommend carotid duplex ultrasonography for screening asymptomatic patients or those without risk factors for atherosclerosis (Class: III, LOE: B). Routine serial extracranial carotid artery imaging is not indicated in disease-free patients on initial vascular imaging and without risk factors (Class: III,
LOE: C).

\section{Carotid plaque texture}

Interestingly, not only carotid plaque burden, but also texture of the carotid plaques has been described as a potential risk predictor of vascular events (15). In that study (15), 298 patients from a prevention clinic who had baseline and 1 year carotid plaque volume and plaque texture measures $(n=376$, based on 9 different texture extraction techniques) were included. Patients were followed-up for the endpoints of MI, TIA and stroke (median: 3.12 years) (15). Combination of changes in texture and total volume yielded the best performance for predicting outcomes (AUC: $0.78 \pm 0.02$ in ROC curve analysis; HR: 6.2, 95\% CI: 4.2-7.9, $\mathrm{P}<0.001$ in Kaplan-Meier curve analysis). Carotid plaque texture change was a predictor of outcomes independent from the Framingham Risk Score (FRS) (HR: 1.4, 95\% CI: 1.3-1.5, $\mathrm{P} \leq 0.002)(15)$.

\section{Carotid plaque ulcer volume}

The impact of total carotid plaque ulcer volume on primary (stroke, TIA or vascular death) and secondary (stroke, TIA, vascular death, MI, revascularization) composite endpoints were evaluated in 349 patients from a prevention clinic who were followed-up for a median 3.17 years (16). Total ulcer volume being $\geq 5 \mathrm{~mm}^{3}$ was associated with adverse outcomes $(\mathrm{P}=0.009$ and $\mathrm{P}=0.017$ for primary and secondary endpoints, 
respectively) (16).

\section{Carotid intima-media thickness}

A meta-analysis (17) that included 13 articles $(n=76,201)$ that investigated the association between carotid IMT and future $\mathrm{CV}$ events, as well as the additional role of carotid IMT on top of existing CV risk assessment tools showed that, despite its association with MI and stroke risk, the addition of carotid IMT to conventional $\mathrm{CV}$ risk prediction models did not result in an improvement $(\mathrm{P}=0.8)$. Another meta-analysis (18) that was published one year before the forementioned meta-analysis had included 14 studies $(n=45,828)$ reported that the addition of common carotid IMT did not yield in a prominent improvement to the FRS in 10-year MI or stroke risk prediction. C statistic was 0.757 (95\% CI: 0.749-0.764) at baseline and 0.759 (95\% CI: $0.752-0.766)$ after addition of common carotid IMT to the model. NRI was $0.8 \%$ (95\% CI: $0.1-1.6 \%$ ).

The utility of carotid IMT measurement for ASCVD prevention with regards to diagnosis and risk stratification is outlined in Table 1 .

\section{Femoral artery ultrasonography}

In recent years, there has been a growing interest in subclinical atherosclerosis imaging in the iliofemoral arterial territories.

The PESA (Progression of Early Subclinical Atherosclerosis) study (19), which enrolled 4,184 asymptomatic patients (no CV risk factors in $38 \%,>2 \mathrm{CV}$ risk factors in $5 \%$ patients), showed that plaques were most frequently found in the iliofemoral arteries (44\%), followed by the carotid arteries (33\%) (19). A substudy of the PESA study ( $\mathrm{n}=3,680$, median 10 -year ASCVD risk: 2.17 , no $\mathrm{CV}$ risk factors in $44 \%$ patients) (20) evaluated plaque burden using $3 \mathrm{D}$ vascular ultrasound. Plaque burden was greater in the femoral arteries compared to the carotids (64 vs. 23.1 $\left.\mathrm{mm}^{3}, \mathrm{P}<0.001\right)$. Plaque burden was associated with ASCVD risk independent of the number of territories affected or plaques $(\mathrm{P}<0.01)$.

The AWHS (Aragon Workers' Health Study) (21) that included 40-59-year-old men $(n=1,423$; no $\mathrm{CV}$ risk factors in $20.7 \%,>2 \mathrm{CV}$ risk factors in $9.9 \%$ patients) also showed that subclinical atherosclerosis, which was assessed using carotid and femoral ultrasonography as well as CACS, was most commonly located at the femoral arteries (54\%). Femoral atherosclerosis had stronger associations with TRFs and positive CACS compared to carotid atherosclerosis.

The utility of femoral artery plaque burden assessment for ASCVD prevention with regards to diagnosis and risk stratification based on European guidelines is outlined in Table 1. However, it has not been mentioned in the American guidelines. "A rational screening plan" for reclassifying FRS was provided in an editorial paper (22) that commented on the study by Laclaustra et al. (21).

\section{Utility of intravascular ultrasound (IVUS)}

Evidence from IVUS studies, including the more extensive arterial remodeling (i.e., larger plaque area and positive remodeling) in unstable clinical presentations compared to patients with stable angina (23) and the increased prevalence of ulcerated non-culprit lesions in MI patients (24), have provided data on pathogenesis of MACE in ASCVD. In addition, IVUS studies have reported plaque features that are related to coronary atherosclerotic burden changes. When adjusted for baseline characteristics, more calcified lesions (represented by baseline calcium index being $\geq$ median) were shown to be associated with a lower rate of change in atheroma burden (progression or regression) (OR: 0.48, 95\% CI: 0.35-0.66, $\mathrm{P}<0.0001)(25)$. Spotty calcification in patients with stable CAD was associated with progression in percent atheroma volume (PAV) (change in PAV adjusted for baseline characteristics: $0.68 \% \pm 0.12 \%$ vs. $0.05 \% \pm 0.17 \%, \mathrm{P}=0.002$ ) (26). IVUS studies have also highlighted the response in coronary atherosclerotic plaque burden to statin therapy. Even in stable CAD with high-risk features $(n=201)$, such as high plaque burden (PAV >63\%), spotty calcification or positive remodeling, statin therapy may cause regression of atherosclerosis (change in PAV: $-0.83 \% \pm 0.53 \%$ vs. $1.87 \% \pm 0.68 \%, \mathrm{P}=0.01)(27)$.

The prognostic value of IVUS on plaque characteristics in ASCVD has been investigated in several studies. A 2-year follow-up of stable CAD patients undergoing IVUS $(\mathrm{n}=4,477)$ showed that the incidence of MI $(1.0 \mathrm{vs} .1 .4 \%$, $\mathrm{P}=1.00)$ and death $(0.0$ vs. $0.1 \%, \mathrm{P}=1.00)$ were similar between those with $(n=201)$ and without $(n=4,276)$ highrisk plaques (HRPs). However, the analysis of 4,137 CAD patients undergoing serial IVUS investigations, who were followed-up for a mean of 21.1 months demonstrated that higher baseline plaque burden (reflected with PAV) was associated with a greater likelihood of MACE, defined as MI, coronary revascularization and death (HR: 1.32, 95\% CI: $1.22-1.42, \mathrm{P}<0.001)(28)$. Greater increase in PAV at follow-up was also associated with greater risk of MACE 
Table 2 The utility of IVUS for ASCVD prevention with regards to diagnosis and risk stratification

\begin{tabular}{|c|c|}
\hline Guidelines & Recommendations \\
\hline $\begin{array}{l}2011 \text { ACCF/AHA/SCAI guidelines for percutaneous } \\
\text { coronary intervention ( } 31 \text { ) }\end{array}$ & IVUS can be useful for angiographically equivocal left main CAD (Class: Ila, LOE: B) \\
\hline $\begin{array}{l}2011 \text { ACCF/AHA/SCAI guidelines for percutaneous } \\
\text { coronary intervention (31) }\end{array}$ & $\begin{array}{l}\text { IVUS may be considered in angiographically-documented moderate luminal } \\
\text { stenosis }(50-70 \%) \text { in the non-left main coronary arteries (Class: Ilb, LOE: B) }\end{array}$ \\
\hline
\end{tabular}

(HR: $1.20,95 \%$ CI: $1.10-1.31, \mathrm{P}<0.001)$. These two parameters remained significant after adjustment for clinical risk factors (28).

In addition to greater plaque burden, findings of PREDICTION (Prediction of Progression of Coronary Artery Disease and Clinical Outcome Using Vascular Profiling of Shear Stress and Wall Morphology) study (29) showed that low shear stress was also an independent predictor of plaques that required revascularization within 1 year in high-risk patients following a percutaneous coronary intervention for an acute coronary syndrome (ACS) (HR: 3.18, 95\% CI: 1.20-8.43, P=0.020).

The utility of IVUS for diagnosis and risk stratification of ASCVD is outlined in Table 2. IVUS is not suitable for primary prevention for ASCVD.

\section{Coronary artery calcium score}

Coronary artery calcium score (CACS) is a relatively simple screening test using ECG-gated non-contrast computed tomography, yet several studies confirmed its powerful prognostic value. A large-scale study $(n=25,253)$ showed that CACS was an independent predictor of allcause mortality during a mean follow-up of 6.8 years when adjusted for baseline characteristics [for CACS $>10$ Agatston units (AU), HR range: 3.61-9.36, $\mathrm{P}<0.0001]$ and 10 -year survival worsened with increasing CACS (99.4\% for $\mathrm{CACS}=0$ vs. $87.8 \%$ for $\mathrm{CACS} \geq 1,000 \mathrm{AU}, \mathrm{P}<0.0001)(32)$. In another study, a baseline CACS of 0 conferred $<1 \%$ mortality in 4,864 asymptomatic low-risk patients followed up for a mean of 14.6 years (33). In the multivariate analysis, CACS was the strongest predictor of all-cause mortality when adjusted for baseline characteristics (HR: 2.67, 95\% CI: 2.29$3.11, \mathrm{P}<0.001)(\mathrm{n}=9,715)$. Increasing CACS remained to be an independent predictor of all-cause mortality when adjusted for FRS and NCEP ATP III (National Cholesterol Education Program Adult Treatment Panel III) (n=9,715) (33).

In addition to the prognostic role of CACS in all-cause mortality, its impact on incident coronary events was also explored. In the Multi-Ethnic Study of Atherosclerosis (MESA) study (34), 6,722 subjects from four ethnic groups who were free from known CVD were followed up for a median of 3.8 years. Increasing CACS was a significant predictor of major coronary events (defined as $\mathrm{MI}$ and death from CAD) (for CACS =1-100 AU, HR: 3.89; for CACS $>300$ AU, HR: 6.84) and any coronary event risk (for CACS =1-100 AU, HR: 3.61; CACS >300 AU, HR: 9.67) after adjusting for TRFs (all $\mathrm{P}<0.001$ ) (34). A substudy (35) of the MESA study undertaken in 3,398 subjects followed-up for a median of 7.6 years showed that in the multivariable model, lnCAC (natural logarithm of CAC) volume score (HR: 1.81, 95\% CI: $1.47-2.23, \mathrm{P}<0.001$ and HR: $1.68,95 \% \mathrm{CI}$ : $1.42-1.98, \mathrm{P}<0.001)$ and CAC density score (HR: $0.73,95 \%$ CI: $0.58-0.91, \mathrm{P}=0.006$ and HR: $0.71,95 \%$ CI: $0.60-0.85$, $\mathrm{P}<0.001$ ) were independent predictors of $\mathrm{CAD}$ events (CAD death, resuscitated cardiac arrest or $\mathrm{MI}$ ) and all CVD events (hard CAD, stroke or stroke death) risk, respectively (35).

A follow-up of MESA study (36) $(n=6,814)$ with median follow-up of 11.1-year showed that 10-year ASCVD (MI, stroke, resuscitated cardiac arrest, CAD deaths) event rates increased across CACS categories independent of age, gender, ethnicity or baseline statin use. Each doubling of CACS was associated with a HR: 1.14 (95\% CI: 1.11-1.17, $\mathrm{P}<0.001$ ) for ASCVD risk (36). 
Inclusion of CACS in the MESA score resulted in improvement in 10-year $\mathrm{CAD}$ risk prediction when added on top of TRFs (Harrell's C-statistic from 0.750 to 0.800) (37). Similarly, the NRI was also improved when CACS was added on top of FRS in the intermediate-risk group of the MESA participants ( $\mathrm{n}=1,330)$ (NRI: 0.659 for incident CAD and NRI: 0.466 for incident CVD) (38). A follow-up of 6,698 subjects from the MESA study showed that even subjects without $\mathrm{CV}$ risk factors could have $\mathrm{CACS}>300 \mathrm{AU}$ (in 5\%), and interestingly subjects having $\geq 3 \mathrm{CV}$ risk factors could have CACS $=0$ AU (35\%) (39). Subjects with $\geq 3 \mathrm{CV}$ risk factors having CACS $=0 \mathrm{AU}$ had lower $\mathrm{CAD}$ event rates compared to those without $\mathrm{CV}$ risk factors but CACS >300 AU (3.1/1,000 person-years vs. 10.9/1,000 personyears), suggesting that CACS may be used for further risk stratification. This was further validated in the multicenter CAC Consortium cohort that enrolled 66,636 primary prevention patients undergoing CACS assessment (40).

The utility of CACS as a risk classifier may be regarded as its biggest advantage in CVD prevention patients. A study comparing 13 negative risk markers among 6,814 participants of the MESA study for the prediction of CAD and all CVD events at 10-year follow-up (41) showed that a negative CACS was the strongest negative risk marker, when adjusted for TRFs. This was assessed using a statistically determined diagnostic likelihood ratio (DLR), where CACS $=0 \mathrm{AU}$ had a mean DLR of 0.41 for all CAD, 0.51 for hard CAD and 0.54 for all CVD (41). The other imaging parameters assessed along with CACS $=0$ were absence of carotid plaque, carotid IMT $<25$ th percentile and change in brachial flow-mediated dilation $>5 \%$ (41). A more recent study including 5,805 BioImage participants investigated the negative risk markers for risk stratification in the elderly population (mean age: 69 years) (42). CACS $=0 \mathrm{AU}$ (mean DLR: 0.20 and 0.41, respectively) and CACS $\leq 10$ AU (mean DLR: 0.20 and 0.48 , respectively) were the strongest negative risk markers of CAD and CVD (42). Other imaging parameters assessed along with CACS were absence of carotid plaque and carotid IMT $<25$ th percentile.

CACS has the potential to transform into clinical therapeutic decision, including identification of patients who may benefit from statin treatment. Applying 2013 ACCF/ AHA guidelines on the treatment of blood cholesterol (43) to the MESA cohort, the investigators showed that in the intermediate-risk group, who had 10-year ASCVD risk of $5-20 \%$, having CACS $=0 \mathrm{AU}$ reclassified the risk below the cut-off for statin consideration (44). Similar results were obtained regarding the down-classification potential of CACS $=0$ AU when 2016 ESC (European Society of Cardiology)/EAS (European Atherosclerosis Society) guidelines on the management of dyslipidemias (45) were applied to the MESA cohort (46). Median 9.4-year followup of a primary prevention cohort $(n=13,644)$ for MACE (defined as a composite of acute MI, stroke and CV death) showed that benefit from statins to reduce MACE was observed in those with positive CACS (HR: 0.76, 95\% CI: $0.60-0.95, \mathrm{P}=0.015$ ), but not in patients with $\mathrm{CACS}=0$ (HR: 1.00, 95\% CI: 0.79-1.27, $\mathrm{P}=0.99$ ) (47). The more elevated the CACS, the more likely the subjects were to benefit from statins $(\mathrm{P}<0.0001)(47)$.

As demonstrated in a meta-analysis of 6 studies (48) (11,256 subjects, mean follow-up: 1.6-6.0 years), once a patient was diagnosed with a positive CACS, they had higher odds of aspirin (OR: 2.6, 95\% CI: 1.8-3.8), lipid-lowering (OR: 2.9, 95\% CI: 1.9-4.4) and blood pressure-lowering (OR: 1.9, 95\% CI: 1.6-2.3) drug initiation; lipid-lowering drug continuation (OR: 2.3, 95\% CI: 1.6-3.3) as well as lifestyle changes, including dietary changes (OR: 1.9, 95\% CI: $1.5-$ 2.5 ) and increase in exercise (OR: 1.8, 95\% CI: 1.4-2.4).

The utility of CACS for diagnosis and risk stratification of ASCVD is outlined in Table 3. An algorithm for the use of CACS in various clinical scenarios is suggested in Figure 1.

\section{CT coronary angiography (CTCA)}

CTCA may diagnose ASCVD and discriminate individuals at risk of MACE by assessing several aspects, including grading luminal stenosis, defining HRP and quantifying plaque burden. CTCA also allows non-invasive functional assessment, including fractional flow reserve calculation derived from CT (FFR-CT) (53-55) and perfusion imaging (56), which are beyond the scope of this review.

\section{Anatomical disease severity assessment}

CTCA may be useful: (I) to detect left main stem or multivessel disease, (II) to diagnose "obstructive" CAD in patients with stable angina and (III) to guide management strategies, including revascularization (57).

When compared with invasive coronary angiography (ICA), CTCA was shown to have excellent negative predictive values both in patient-based $(97 \%, 95 \% \mathrm{CI}$ : 94-100\%) and segment-based (99\%, 95\% CI: 98-99\%) analyses $(\mathrm{n}=360)(58)$.

The CONFIRM (Coronary CT Angiography Evaluation for Clinical Outcomes: an International Multicenter) 
Table 3 The utility of CACS for ASCVD prevention with regards to diagnosis and risk stratification

Guidelines
2019 ESC/EAS Guidelines for the management
dyslipidemias (10)
2019 ACCF/AHA guidelines on the primary
prevention of CVD (49)
2018 ACCF/AHA cholesterol clinical practice
guidelines (50)

guidelines (50)

2016 SCCT/STR guidelines for coronary artery calcium scoring of non-contrast noncardiac chest CT scans (51)

2010 ACCF/SCCT/ACR/AHA appropriate use criteria for cardiac computed tomography (52)

2010 ACCF/SCCT/ACR/AHA appropriate use criteria for cardiac computed tomography (52)
Recommendations

CACS can be useful in low-moderate CV risk subjects as a risk modifier (Class: Ila, LOE: B)

It is reasonable to measure CACS in intermediate (10-year ASCVD risk: 7.5-20\%) or selected borderline-risk (10-year ASCVD risk: 5.0-7.5\%) adults for ASCVD risk-based preventive interventions (Class: Ila, LOE: B)

It is reasonable to measure CACS in intermediate (10-year ASCVD risk: 7.5-20\%) or selected borderline-risk (10-year ASCVD risk: 5.0-7.5\%) adults to determine statin eligibility if the decision about statin therapy is equivocal (Class: Ila, LOE: B):

- defer statin therapy and reassess in 5-10 years if CACS =0 AU (unless higher risk conditions are present)

- $\quad$ initiate statin therapy in subjects $\geq 55$ years if CACS: 1-99 AU

- $\quad$ initiate statin therapy if CACS $\geq 100 \mathrm{AU}$

Opportunistic CACS screening is recommended in all patients aged $\geq 40$ years undergoing non-contrast chest CT (Class: I). Estimation of CACS as none, mild, moderate or severe is indicated (Class I)

CACS is reasonable in low CAD risk patients with family history of premature CAD and intermediate $C A D$ risk patients for detection of CAD and further risk assessment (Appropriate use criteria: 7 for both scenarios)

CACS is not appropriate in low-risk asymptomatic patients (Appropriate use criteria: 2)

ACCF, American College of Cardiology; ACR, American College of Radiology; AHA, American Heart Association; ASCVD, atherosclerotic cardiovascular disease; CACS, coronary artery calcium score; CAD, coronary artery disease; CT, computed tomography; CV, cardiovascular; CVD, cardiovascular disease; EAS, European Atherosclerosis Society; ESC, European Society of Cardiology; LOE, level of evidence; SCCT, Society of Cardiovascular Computed Tomography; STR, Society of Thoracic Radiology.
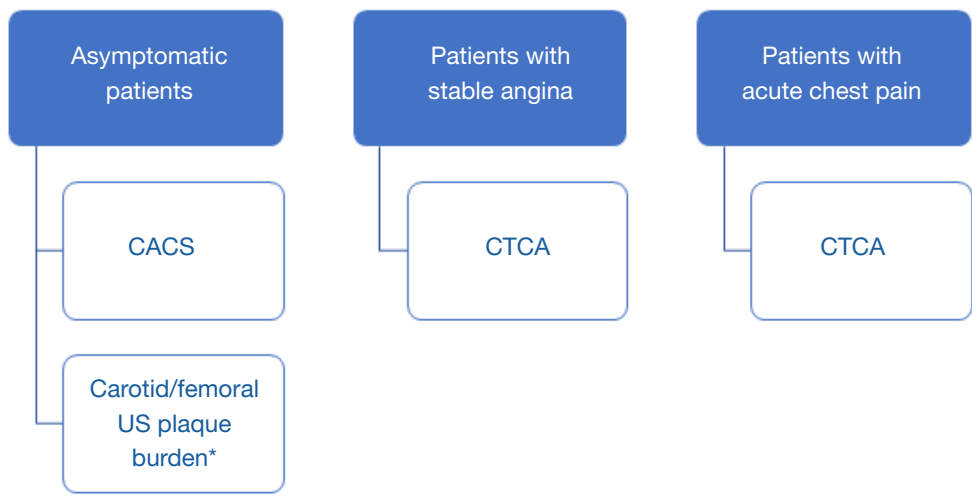

Figure 1 Figure summarizing the first-line cardiovascular imaging strategy for risk stratification for ASCVD in primary prevention cohort. Note that patients presenting with stable angina and acute chest pain should be clinically evaluated, and undergo CTCA if clinically appropriate. ASCVD, atherosclerotic cardiovascular disease; CACS, coronary artery calcium score; CTCA, CT coronary angiography; US, ultrasonography. *Not present in American guidelines. 
registry (59), which included 15,207 intermediate-risk patients undergoing CTCA followed up for a mean of 2.3 years, showed that patients said to have no and mild CAD according to CTCA had low rates of ICA $(2.5 \%$ and $8.3 \%$, respectively) and revascularization $(0.3 \%$ and $2.5 \%$, respectively) rates. Predictors of ICA in patients with nonobstructive stenosis on CTCA obtained from the multivariate model were advancing age, typical chest pain, mild left main stenosis, mild proximal left anterior descending artery stenosis, mild proximal left circumflex artery stenosis and mild proximal right coronary artery stenosis. In patients with nonobstructive $\mathrm{CAD}$, the survival was worse in those undergoing ICA (HR: 2.25, 95\% CI: 1.16-4.39, P=0.011) (59). However, in those with obstructive $\mathrm{CAD}$, the survival was better in those undergoing ICA (HR: 0.61, 95\% CI: 0.38 0.99, $\mathrm{P}=0.047$ ) (59).

Five-year follow-up of the CONFIRM registry (60) $(\mathrm{n}=5,632)$ showed that there was a strong association between degree of CAD defined by CTCA and MACE (defined as composite all-cause mortality and non-fatal MI). There was an independent association between higher MACE risk and increased severity and extent of CAD (HR: 2.25 for non-obstructive CAD, HR: 2.86 for obstructive 1-vessel CAD, HR: 3.46 for 2-vessel CAD and HR: 4.68 for 3 -vessel obstructive CAD (all $\mathrm{P}<0.001$ ). Similar results were obtained from a Danish multicenter study $(\mathrm{n}=16,949)(61)$.

In the PROMISE (Prospective Multicenter Imaging Study for Evaluation of Chest Pain) trial (62), 10,003 symptomatic patients that were suspected from CAD were randomized to initial CTCA or functional testing and followed-up for a median of 25 months. Composite primary endpoint of hospitalization for unstable angina or major procedural complications, $\mathrm{MI}$, any-cause death were similar in the CTCA $(3.3 \%)$ and functional-testing $(3.0 \%)$ groups $(\mathrm{P}=0.75)$ (62). More patients in the CTCA group underwent ICA within 90 days (12.2 vs. 8.1\%), but no obstructive CAD on ICA was more common in the functional testing group ( $4.3 \%$ vs. $3.4 \%, \mathrm{P}=0.02)$ (62).

In the Scottish Computed Tomography of the Heart (SCOT-HEART) trial (63), 4,416 patients with suspected stable angina were randomized to standard care plus CTCA versus standard care alone (1:1). Addition of CTCA led to significant changes in reclassification of diagnosis (change in 6-week diagnosis of CAD: $27 \%$ in CTCA vs. $1 \%$ in standard care; change in 6-week diagnosis of angina: $23 \%$ in CTCA vs. $1 \%$ in standard care; both $\mathrm{P}<0.001$ ), planned investigations (change: $15 \%$ vs. $1 \%, \mathrm{P}<0.001$ ) and antianginal treatments (change: $9 \%$ vs. $1 \%, \mathrm{P}<0.0001$ ), associated with a trend towards reduction in fatal and nonfatal MI (HR: 0.62, 95\% CI: 0.38-1.01, P=0.052) during follow-up (median: 1.7 years). A follow-up of SCOTHEART trial (64) (median follow-up: 4.8 years) showed that the 5-year rate of death from CAD or non-fatal MI was lower in the CTCA group compared to standard care alone (HR: 0.59, 95\% CI: 0.41-0.84, P=0.004).

The utility of CTCA for diagnosis and risk stratification of ASCVD is outlined in Table 4. Although not performed with the aim of primary prevention, its results enable risk stratification in patients without prior $\mathrm{CV}$ events. An algorithm for the use of CTCA in various clinical scenarios is suggested in Figure 1.

According to CAD-RADS (Coronary Artery Disease Reporting and Data System) reporting system (57), degree of maximal luminal stenosis is used to make categorizations. In patients classified to CAD-RADS 3 to 5, further cardiac testing (combinations of functional testing, ICA or revascularization) is suggested for stable chest pain or low to intermediate-risk acute chest pain patients. CAD-RADS 3 refers to "moderate stenosis", defined as maximal luminal stenosis of 50-69\%. CAD-RADS 4A refers to "severe stenosis", defined as maximal luminal stenosis of $70-99 \%$ in single-vessel or 2-vessels, whereas CAD-RADS 4B refers to "severe stenosis" (>70\%) in 3-vessels or left main stenosis $>50 \%$. CAD-RADS 5 refers to total coronary occlusion (100\%). Yet, patients that belong to CAD-RADS 1 (1-24\% of maximal luminal stenosis) and 2 (25-49\% of maximal luminal stenosis) categories require preventive management strategies (lifestyle modification, drug therapies) in order to control the atherosclerotic burden.

\section{Plaque characterization}

CTCA enables assessment of HRP features (positive remodeling, spotty calcification and low-attenuation plaque) that were reported to be more prevalent in culprit ACS lesions versus stable plaques (67), as well as features that are more likely to result in ACS diagnosis during index hospitalization (68) or at follow-up (69). Positive remodeling and/or low-attenuation plaques on CTCA were independent predictors of ACS at a mean of 27-month follow-up $(\mathrm{n}=1,059)$ (HR: 22.8, 95\% CI: 6.9-75.2, $\mathrm{P}<0.001)$ (69). Plaque composition assessment obtained from CTCA was validated histologically (70) and through virtual histology-IVUS (VH-IVUS) $(71,72)$ or optical coherence tomography (OCT) (73) studies. In the CADRADS reporting system (56), a vulnerable plaque is defined 
Table 4 The utility of CTCA for ASCVD prevention with regards to diagnosis and risk stratification

\begin{tabular}{ll}
\hline Guidelines & Recommendations \\
\hline $\begin{array}{l}2019 \text { ESC/EAS Guidelines for the management of } \\
\text { dyslipidemias (10) }\end{array}$ & $\begin{array}{l}\text { Multivessel coronary disease (two major epicardial arteries having }>50 \% \\
\text { stenosis on CTCA) is accepted as evidence for ASCVD and places the } \\
\text { patient in the very high CV risk group }\end{array}$ \\
$\begin{array}{l}2019 \text { ESC Guidelines for the diagnosis and management of } \\
\text { chronic coronary syndromes (65) }\end{array}$ & $\begin{array}{l}\text { CTCA or non-invasive functional imaging is recommended as the first-line } \\
\text { test in symptomatic patients in whom clinical assessment is insufficient for } \\
\text { obstructive CAD diagnosis (Class I, LOE: B) }\end{array}$ \\
$\begin{array}{l}\text { CTCA is not recommended in conditions that preclude good image quality } \\
\text { chronic coronary syndromes (65) }\end{array}$ & $\begin{array}{l}\text { (such as obesity, extensive coronary calcification, arrhythmia, inability to } \\
\text { cooperate with commands) (Class III, LOE: C) }\end{array}$ \\
$\begin{array}{l}\text { It is recommended to offer CTCA as the first-line test in subjects with } \\
\text { recent onset: assessment and diagnosis [CG95] (66) }\end{array}$ & $\begin{array}{l}\text { suspected CAD in whom stable angina cannot be excluded } \\
\text { CTCA may be a reasonable approach in asymptomatic high CAD risk } \\
\text { cardiac computed tomography (52) }\end{array}$ \\
$\begin{array}{l}\text { patients without known CAD for detection of CAD and further risk } \\
\text { assessment (Appropriate use criteria: 4) }\end{array}$ \\
$\begin{array}{l}\text { CTCA is not appropriate in low and intermediate-risk groups (Appropriate } \\
\text { cardiac computed tomography (52) }\end{array}$
\end{tabular}

ACCF, American College of Cardiology Foundation; ACR, American College of Radiology; AHA, American Heart Association; ASCVD, atherosclerotic cardiovascular disease; CAD, coronary artery disease; CTCA, CT coronary angiography; CV, cardiovascular; EAS, European Atherosclerosis Society; ESC, European Society of Cardiology; NICE, National Institute for Health and Care Excellence; SCCT, Society of Cardiovascular Computed Tomography.

as presence of $\geq 2$ of the following plaque characteristics: (I) spotty calcification, (II) napkin-ring sign, (III) positive remodeling, (IV) low attenuation (Figure 2).

There are several studies evaluating the impact of CTCA plaque characteristics on MACE. At a mean 3.9-year follow-up of 3,158 patients with suspected or known CAD undergoing CTCA, patients with HRP (low attenuation or positive remodeling) had a 10 -fold higher fatal and nonfatal ACS rate than those without HRP [HR: 13.13, 95\% CI: 3.80-82.66, $\mathrm{P}<0.0001$ in $\mathrm{HRP}+$ /significant stenosis (SS)- group; HR: 17.24, 95\% CI: 4.87-109.47, P<0.0001 in $\mathrm{HRP}+/ \mathrm{SS}+$ group], however the cumulative event number was similar between two groups since the number of HRP+ subjects was 10-fold lower (74). A study with longer follow-up (75) (mean 7.8 years) showed that low attenuation plaques (HR: 4.5, 95\% CI: 1.4-14.8, $\mathrm{P}<0.001$ ), napkin-ring sign (HR: 7.0, 95\% CI: 2.0-13.6, $\mathrm{P}<0.001$ ) and spotty calcification (HR: 2.6, 95\% CI: $1.1-6.5, \mathrm{P}<0.001$ ) were significant predictors of MACE (defined as ACS) after adjusting for TRFs in 1,469 low-to-intermediate risk patients. Most recently, the 5-year follow-up results of SCOT-HEART trial $(n=1,769)$ showed that although HRP characteristics were more associated with higher MACE rates, these were not independent of CACS (76).
A recent study also showed that HRP was not an independent predictor of the progression of an individual non-obstructive coronary artery stenosis lesion $(n=1,297$ patients, $\mathrm{n}=3,049$ lesions, mean interscan interval: 3.8 years) (77). In the multivariate model including TRFs, medications, change in low-density lipoprotein levels, total PAV, \% diameter stenosis and HRP, only baseline total PAV and $\%$ diameter stenosis were independent predictors of progression to obstructive lesions (HR: 1.04, 95\% CI: 1.021.07 and 95\% CI: 1.07, 95\% CI: 1.04-1.10, respectively, both $\mathrm{P}<0.05)(77)$.

\section{Plaque burden quantification}

Semiautomated segmentation technology on CTCA that helps to quantify plaque burden has been used in many research studies $(78,79)$. Incremental value of semiautomated plaque quantification when added to clinically determined risk features and conventional CTCA measures for predicting ACS was demonstrated in a study including 1,650 patients followed-up for a mean of 26 months for ACS (AUC from 0.64 to 0.79, $\mathrm{P}=0.047$ ) (78). Total plaque burden identified using CTCA was also shown to have greater diagnostic accuracy than anatomical stenosis 


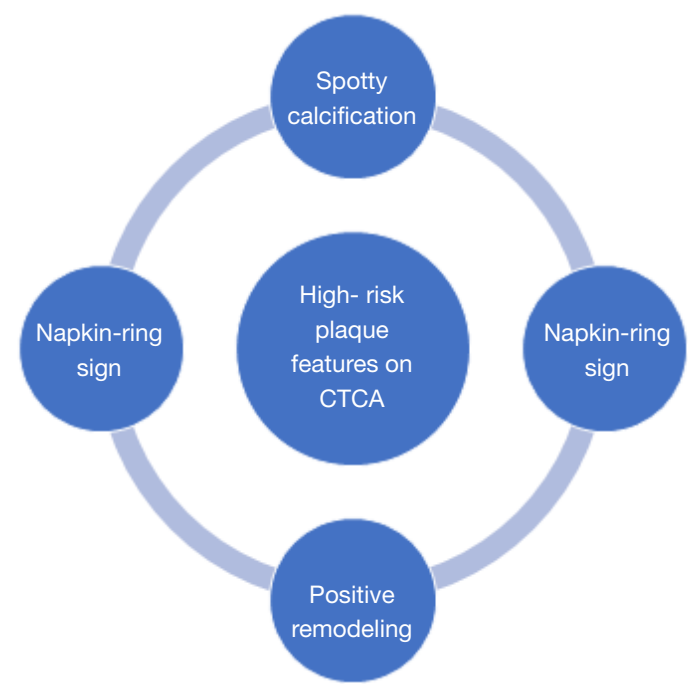

Figure 2 High-risk plaque features depicted on CTCA: A vulnerable plaque is defined as presence of $\geq 2$ of the plaque characteristics shown above. The high-risk features are described in the Society of Cardiovascular Computed Tomography consensus document by Cury et al. (57). CTCA, CT coronary angiography.

severity for prediction of ischemic lesions defined by FFR-ICA (AUC: 0.83 for total plaque burden vs. 0.68 for stenosis, $\mathrm{P}=0.04)$ (79).

\section{Other applications of CTCA}

CTCA also enables qualitative and quantitative assessment of the perivascular adipose tissue, which has been suggested to be a predictor of adverse outcomes in ASCVD $(80,81)$.

High perivascular fat attenuation index (FAI) (cutoff $\geq 70.1 \mathrm{HU}$ ) around the right coronary artery was found to be an independent predictor of all-cause (HR: 2.55, $\mathrm{P}<0.001$ and HR: 3.69, $\mathrm{P}<0.001$, respectively) and cardiac mortality (HR: 9.04, $\mathrm{P}<0.001$ and HR: 5.62, $\mathrm{P}<0.001$, respectively) in both derivation ( $\mathrm{n}=1,872$, median follow-up: 72 months) and validation cohorts $(n=2,040$, median follow-up: 54 months) when adjusted for TRFs, tube voltage and CTCAderived measures, including modified Duke CAD index and number of HRP features (80).

A recent study reported that a fat radiomic profile (FRP), a machine-learning based algorithm for the radiomic features of the perivascular adipose tissue extracted from CTCA images, was able to discriminate patients that would experience MACE within 5 years of the CTCA scan (C-statistic: $0.77,95 \%$ CI: $0.62-0.93$ ) and provide additional prognostic information to predict MACE when added to a model that included TRFs, CACS, coronary stenosis and HRP features on CTCA (Delta C-statistic: $0.126, \mathrm{P}<0.001)(81)$.

\section{Magnetic resonance imaging (MRI)}

\section{Carotid MRI}

MR angiography (MRA) combines both angiography and soft tissue assessment and may be used to assess carotid artery stenosis $(82,83)$. Black blood carotid artery imaging using turbo spin echo sequence was also shown to be useful to evaluate wall thickness and plaque eccentricity (standard deviation of wall thickness) in the carotid arteries (84). In that study, which was performed in 195 patients that were $\geq 50$ years and had $\geq 2 \mathrm{CV}$ risk factors, plaque eccentricity was independently associated with prior MACE (defined as history of TIA, stroke, ACS or coronary revascularization) after adjusting for traditional risk factors (OR: 1.80, 95\% CI: 1.18-2.76) (84).

There are other applications of MRI with respect to atherosclerosis imaging of the carotid arteries, including ultrasmall superparamagnetic particles of iron oxide (USPIOs) imaging to track macrophage infiltration (i.e., inflammation) $(85,86)$; T1-weighted high-intensity plaque (HIP) imaging to identify to identify plaque rupture and intraplaque hemorrhage $(87,88)$ and $\mathrm{T} 2$-mapping to quantify lipid content and distribution $(89,90)$. 
T1-weighted HIP imaging of the carotid arteries was shown to be a predictor of future coronary events, defined as unstable angina pectoris or emergency hospitalization for recurrent angina, non-fatal MI, cardiac death, in subjects with stable CAD at a mean of 38.3 months $(n=217)$ (Number of composite endpoint: 31 in HIP+ group $v s .5$ in HIPgroup, $\mathrm{P}<0.001$ by log-rank test) (91).

2010 ACCF/ACR/AHA/NASCI (North American Society for Cardiovascular Imaging)/SCMR (Society of Cardiovascular Magnetic Resonance) expert consensus document on cardiovascular magnetic resonance (92) states that CMR may be used for determining the presence and extent of stenosis in the carotid arteries. However, carotid MRI is not clinically implicated for risk stratification in ASCVD.

\section{Cardiac magnetic resonance imaging (CMR)}

Besides its angiographic utility, CMR also has the potential to characterize high-risk coronary atherosclerosis based on the utility of various sequences (93): late gadolinium enhancement imaging to identify large necrotic core; T1-weighted black blood imaging to identify positive remodeling $(94,95)$; T1-weighted HIP imaging to identify subclinical plaque rupture, angiogenesis and intraplaque hemorrhage $(96,97)$; USPIO imaging to track macrophage infiltration (i.e., inflammation) (98). However, these techniques are not currently in routine clinical use.

In a substudy of MESA cohort ( $\mathrm{n}=38$ subjects; 88 arterial segments) (94), in which the inclusion was on a voluntary basis, coronary artery wall thickness was measured using black blood imaging. In subjects that had CACS $=0(n=23)$, the coronary walls were thicker in those that had $\geq 2$ TRFs compared to those with $<2$ TRFs (Mean thickness: $1.95 \mathrm{vs}$. $1.70 \mathrm{~mm}, \mathrm{P}<0.05)$.

A study suggested the plaque-to-myocardium signal intensity ratio obtained from non-contrast T1-weighted imaging was an independent predictor of adverse events (cardiac death, ACS or ischemia-driven percutaneous coronary intervention owing to progressive angina pectoris) at a median follow-up of 55 months when adjusted for TRFs in patients with known or suspected CAD (HR: 3.96, 95\% CI: $1.92-8.17, \mathrm{P}<0.001)(\mathrm{n}=568)(96)$. Plaqueto-myocardium signal intensity ratio obtained using T1weighted imaging was also reported to be an independent predictor of periprocedural myocardial injury in patients undergoing elective percutaneous coronary intervention $(\mathrm{n}=57)(97)$.
According to 2010 ACCF/ACR/AHA/NASCI/SCMR expert consensus document on cardiovascular magnetic resonance (92), CMR may be used to identify coronary artery luminal patency without exposure to iodinated contrast or radiation. However, CMR is not clinically implicated for risk stratification in ASCVD.

\section{Positron emission tomography}

Potential radionuclide agents and targets for imaging ASCVD include ${ }^{18} \mathrm{~F}$-labeled fluorodeoxyglucose $\left({ }^{18} \mathrm{~F}\right.$-FDG) (99-101) and ${ }^{68} \mathrm{Ga}\left({ }^{68} \mathrm{Gallium}\right)$-labeled DOTATE $(102,103)$ for assessing the severity of inflammation; ${ }^{18} \mathrm{~F}$-labeled sodium fluoride $\left({ }^{18} \mathrm{~F}-\mathrm{NaF}\right)$ (104-106) for microcalcification. Although most commonly combined with CT, PET may also be combined with MRI as reported in a recent study (107).

With respect to inflammation imaging of the coronary arteries using PET, studies using ${ }^{18} \mathrm{~F}-\mathrm{FDG}(99)$ and ${ }^{68} \mathrm{Ga}-$ DOTATE (102) as tracers reported higher uptake in the setting of ACS compared to stable CAD (99) and in culprit arteries compared to non-culprit arteries in the setting of ACS (102), respectively.

Regarding imaging of microcalcification in the coronary arteries, studies using ${ }^{18} \mathrm{~F}-\mathrm{NaF}$ as tracers assessed the relationship between tracer uptake and CACS (104); the comparison of tracer uptake between culprit and nonculprit lesions in the setting of ACS (105), as well as HRPs and non-HRPs in the setting of stable CAD (105). A moderate correlation of CACS with ${ }^{18} \mathrm{~F}-\mathrm{NaF}$ uptake was observed in high tracer uptake group of patients only $(n=40)$ $(\mathrm{r}=0.652, \mathrm{P}<0.001)(104)$. Interestingly, $40 \%$ of subjects that had CACS $>1,000$ AU had normal uptake of the radiolabeled tracer and $5 \%$ of subjects with CACS 1-100 AU had increased uptake (104).

${ }^{18} \mathrm{~F}-\mathrm{NaF}$ uptake was reported to be higher in culprit lesions compared to non-culprit lesions in the setting of ACS (Median target-to-background ratio: 1.66 vs. 1.24, $\mathrm{P}<0.0001)(\mathrm{n}=40)$, where ${ }^{18} \mathrm{~F}-\mathrm{FDG}$ uptake was similar within groups $(\mathrm{P}=0.34)(105) .{ }^{18} \mathrm{~F}-\mathrm{NaF}$ uptake was also found to be significantly higher in HRPs determined using IVUS compared to non-HRPs in stable CAD patients $(n=40)(105)$. Increased ${ }^{18} \mathrm{~F}-\mathrm{NaF}$ uptake was also reported to correspond to histological evidence of plaque rupture, macrophage infiltration, active calcification, apoptosis and necrosis (all $\mathrm{P}<0.05)$ (in 9 carotid endarterectomy specimens) (105).

A recent prospective study showed that degree of preangioplasty inflammation and micro-calcification assessed using ${ }^{18} \mathrm{~F}-\mathrm{FDG}$ and ${ }^{18} \mathrm{~F}-\mathrm{NaF}$ PET/CT imaging of the 
Table 5 Multimodality cardiovascular imaging modalities for ASCVD prevention

\begin{tabular}{|c|c|c|c|c|c|c|}
\hline & $\begin{array}{c}\text { Non-invasive vascular } \\
\text { ultrasonography }\end{array}$ & $\begin{array}{l}\text { Intravascular } \\
\text { ultrasonography }\end{array}$ & $\begin{array}{c}\text { Coronary } \\
\text { artery calcium } \\
\text { score }\end{array}$ & $\begin{array}{c}\text { Computed } \\
\text { tomography of } \\
\text { coronary arteries }\end{array}$ & $\begin{array}{c}\text { Magnetic } \\
\text { resonance imaging }\end{array}$ & $\begin{array}{l}\text { Positron emission } \\
\text { tomography }\end{array}$ \\
\hline $\begin{array}{l}\text { Contrast/tracer } \\
\text { agent exposure }\end{array}$ & - & $\begin{array}{c}+ \text { (during coronary } \\
\text { angiography) }\end{array}$ & - & + & $\begin{array}{c}\text { +/- (IV gadolinium- } \\
\text { based agent may } \\
\text { be administered in } \\
\text { select cases) }\end{array}$ & + \\
\hline $\begin{array}{l}\text { Plaque burden } \\
\text { assessment }\end{array}$ & + & + & + & + & + & - \\
\hline $\begin{array}{l}\text { Plaque composition } \\
\text { assessment }\end{array}$ & - & ++ & - & ++ & ++ & + \\
\hline $\begin{array}{l}\text { Inflammation } \\
\text { assessment }\end{array}$ & - & - & - & - & + & ++ \\
\hline $\begin{array}{l}\text { Risk modifier in } \\
\text { guidelines }\end{array}$ & + & - & +++ & + & - & - \\
\hline
\end{tabular}

ASCVD, atherosclerotic cardiovascular disease; CT, computed tomography; IV, intravenous.

superficial femoral artery predicted arterial re-stenosis at 1 year in symptomatic peripheral artery disease patients undergoing angioplasty $(n=40)(101)$. However, more studies are needed to understand if the vascular inflammation degree has a prognostic role for risk stratification in ASCVD prevention patients.

Table 5 provides an overview of the current imaging approaches for the evaluation of ASCVD. In clinical practice, the type of cardiovascular imaging modality used for ASCVD depends on various factors, including patient characteristics, patient preferences and institution characteristics, resources and expertise (Figure 3).

\section{Other imaging methods for ASCVD risk evaluation}

The utility of retinal vessel imaging for prediction of ASCVD risk was investigated in recent studies. At a mean of 16-year follow-up of 10,470 subjects without known CVD from the ARIC study undergoing retinal photography, narrower retinal arterioles and wider retinal venules were associated with higher rates of adverse outcomes (108). When adjusted for PCE (Pooled Cohort Equation) risk score, narrowing in arteriole and widening in venule were significant predictors of ischemic stroke (HR: 1.06, $\mathrm{P}=0.020$; HR: $1.13, \mathrm{P}<0.001$, respectively) and death (HR: 1.14 , $\mathrm{P}=0.013$; HR: $1.18, \mathrm{P}=0.001$, respectively) in both genders, as well as CAD in women (HR: 1.13, $\mathrm{P}=0.012$; HR: 1.10 , $\mathrm{P}=0.040$, respectively) but not in men. Further research on this topic is required before implementing retinal vessel imaging into clinical practice.

\section{Conclusions}

Arterial ultrasonography and CT imaging techniques including CACS, are the current mainstay imaging modalities for risk stratification in ASCVD in routine clinical practice. Additional imaging modalities, including MRI and PET, also have potentially important emerging 


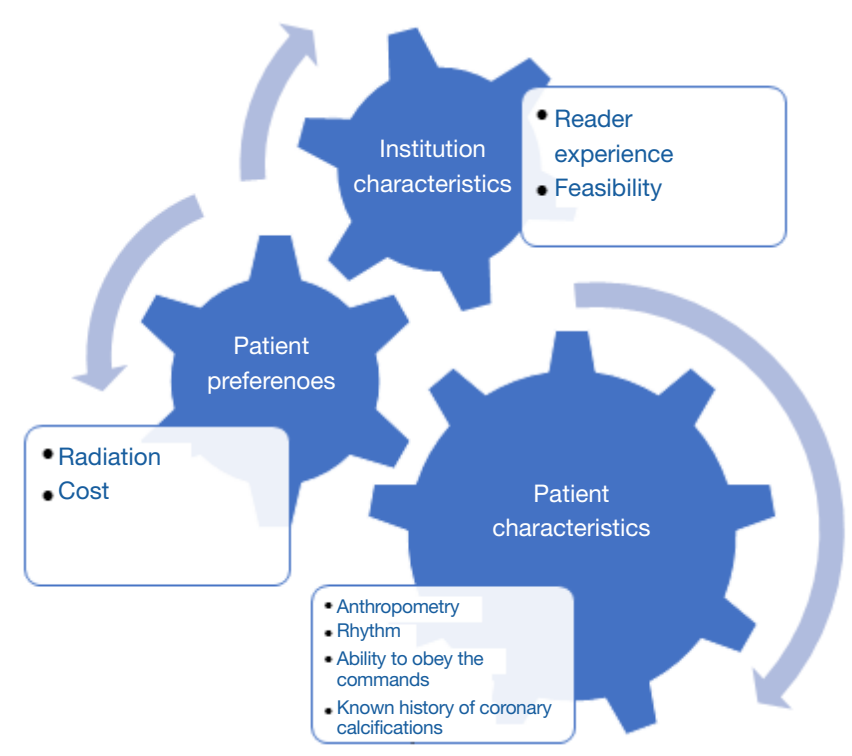

Figure 3 A summary of factors that influence the cardiovascular imaging approach of choice.

roles in ASCVD risk stratification. The selected imaging approach for ASCVD evaluation ultimately should be individualized for each patient based on various factors, including patient characteristics, and patient preferences, as well as institution characteristics, resources and expertise.

\section{Acknowledgments}

Funding: Dr. Kocyigit received personal non-commercial grant from the Turkish Society of Cardiology at the time of work.

\section{Footnote}

Provenance and Peer Review: This article was commissioned by the editorial office, Cardiovascular Diagnosis and Therapy for the series "Heart Valve Disease". The article has undergone external peer review.

Conflicts of Interest: All authors have completed the ICMJE uniform disclosure form (available at http://dx.doi. org/10.21037/cdt-19-654). The series "Heart Valve Disease" was commissioned by the editorial office without any funding or sponsorship. BX served as the unpaid Guest Editor of the series. Dr. Kocyigit reports that she received personal non-commercial grant from the Turkish Society of Cardiology during the time of work. The authors have no other conflicts of interest to declare.
Ethical Statement: The authors are accountable for all aspects of the work in ensuring that questions related to the accuracy or integrity of any part of the work are appropriately investigated and resolved.

Open Access Statement: This is an Open Access article distributed in accordance with the Creative Commons Attribution-NonCommercial-NoDerivs 4.0 International License (CC BY-NC-ND 4.0), which permits the noncommercial replication and distribution of the article with the strict proviso that no changes or edits are made and the original work is properly cited (including links to both the formal publication through the relevant DOI and the license). See: https://creativecommons.org/licenses/by-nc-nd/4.0/.

\section{References}

1. Libby P, Buring JE, Badimon L, et al. Atherosclerosis. Nat Rev Dis Primers 2019;5:56.

2. World Health Organization. The top 10 causes of death. May 2018. Available online: http://www.who.int/newsroom/fact-sheets/detail/the-top-10-causes-of-death

3. Antman EM, Loscalzo J. Precision medicine in cardiology. Nat Rev Cardiol 2016;13:591-602.

4. Rana JS, Tabada GH, Solomon MD, et al. Accuracy of the Atherosclerotic Cardiovascular Risk Equation in a Large Contemporary, Multiethnic Population. J Am Coll Cardiol 
2016;67:2118-30.

5. Nambi V, Chambless L, Folsom AR, et al. Carotid intimamedia thickness and presence or absence of plaque improves prediction of coronary heart disease risk: the ARIC (Atherosclerosis Risk In Communities) study. J Am Coll Cardiol 2010;55:1600-7.

6. Spence JD, Eliasziw M, DiCicco M, et al. Carotid plaque area: a tool for targeting and evaluating vascular preventive therapy. Stroke 2002;33:2916-22.

7. Baber U, Mehran R, Sartori S, et al. Prevalence, impact, and predictive value of detecting subclinical coronary and carotid atherosclerosis in asymptomatic adults: the BioImage study. J Am Coll Cardiol 2015;65:1065-74.

8. Sillesen H, Muntendam P, Adourian A, et al. Carotid plaque burden as a measure of subclinical atherosclerosis: comparison with other tests for subclinical arterial disease in the High Risk Plaque BioImage study. JACC Cardiovasc Imaging 2012;5:681-9.

9. Wannarong T, Parraga G, Buchanan D, et al. Progression of carotid plaque volume predicts cardiovascular events. Stroke 2013;44:1859-65.

10. Mach F, Baigent C, Catapano AL, et al. 2019 ESC/EAS Guidelines for the management of dyslipidaemias: lipid modification to reduce cardiovascular risk. Eur Heart J 2020;41:111-88.

11. Piepoli MF, Hoes AW, Agewall S, et al. 2016 European Guidelines on cardiovascular disease prevention in clinical practice: The Sixth Joint Task Force of the European Society of Cardiology and Other Societies on Cardiovascular Disease Prevention in Clinical Practice (constituted by representatives of 10 societies and by invited experts)Developed with the special contribution of the European Association for Cardiovascular Prevention \& Rehabilitation (EACPR). Eur Heart J 2016;37:2315-81.

12. Goff DC, Jr., Lloyd-Jones DM, Bennett G, et al. 2013 ACC/AHA guideline on the assessment of cardiovascular risk: a report of the American College of Cardiology/ American Heart Association Task Force on Practice Guidelines. J Am Coll Cardiol 2014;63:2935-59.

13. Goldstein LB, Bushnell CD, Adams RJ, et al. Guidelines for the primary prevention of stroke: a guideline for healthcare professionals from the American Heart Association/American Stroke Association. Stroke 2011;42:517-84.

14. Brott TG, Halperin JL, Abbara S, et al. 2011 ASA/ACCF/ AHA/AANN/AANS/ACR/ASNR/CNS/SAIP/SCAI/ SIR/SNIS/SVM/SVS guideline on the management of patients with extracranial carotid and vertebral artery disease: a report of the American College of Cardiology Foundation/American Heart Association Task Force on Practice Guidelines, and the American Stroke Association, American Association of Neuroscience Nurses, American Association of Neurological Surgeons, American College of Radiology, American Society of Neuroradiology, Congress of Neurological Surgeons, Society of Atherosclerosis Imaging and Prevention, Society for Cardiovascular Angiography and Interventions, Society of Interventional Radiology, Society of NeuroInterventional Surgery, Society for Vascular Medicine, and Society for Vascular Surgery. J Am Coll Cardiol 2011;57:e16-94.

15. van Engelen A, Wannarong T, Parraga G, et al. Threedimensional carotid ultrasound plaque texture predicts vascular events. Stroke 2014;45:2695-701.

16. Kuk M, Wannarong T, Beletsky V, et al. Volume of carotid artery ulceration as a predictor of cardiovascular events. Stroke 2014;45:1437-41.

17. van den Oord SC, Sijbrands EJ, ten Kate GL, et al. Carotid intima-media thickness for cardiovascular risk assessment: systematic review and meta-analysis. Atherosclerosis 2013;228:1-11.

18. Den Ruijter HM, Peters SA, Anderson TJ, et al. Common carotid intima-media thickness measurements in cardiovascular risk prediction: a meta-analysis. JAMA 2012;308:796-803.

19. Fernandez-Friera L, Penalvo JL, Fernandez-Ortiz A, et al. Prevalence, Vascular Distribution, and Multiterritorial Extent of Subclinical Atherosclerosis in a Middle-Aged Cohort: The PESA (Progression of Early Subclinical Atherosclerosis) Study. Circulation 2015;131:2104-13.

20. Lopez-Melgar B, Fernandez-Friera L, Oliva B, et al. Subclinical Atherosclerosis Burden by 3D Ultrasound in Mid-Life: The PESA Study. J Am Coll Cardiol 2017;70:301-13.

21. Laclaustra M, Casasnovas JA, Fernandez-Ortiz A, et al. Femoral and Carotid Subclinical Atherosclerosis Association With Risk Factors and Coronary Calcium: The AWHS Study. J Am Coll Cardiol 2016;67:1263-74.

22. Nicolaides A, Panayiotou AG. Screening for Atherosclerotic Cardiovascular Risk Using Ultrasound. J Am Coll Cardiol 2016;67:1275-7.

23. Schoenhagen P, Ziada KM, Kapadia SR, et al. Extent and direction of arterial remodeling in stable versus unstable coronary syndromes : an intravascular ultrasound study. Circulation 2000;101:598-603.

24. Schoenhagen P, Stone GW, Nissen SE, et al. Coronary plaque morphology and frequency of ulceration distant 
from culprit lesions in patients with unstable and stable presentation. Arterioscler Thromb Vasc Biol 2003;23:1895-900.

25. Nicholls SJ, Tuzcu EM, Wolski K, et al. Coronary artery calcification and changes in atheroma burden in response to established medical therapies. J Am Coll Cardiol 2007;49:263-70.

26. Kataoka Y, Wolski K, Uno K, et al. Spotty calcification as a marker of accelerated progression of coronary atherosclerosis: insights from serial intravascular ultrasound. J Am Coll Cardiol 2012;59:1592-7.

27. Kataoka Y, Wolski K, Balog C, et al. Progression of coronary atherosclerosis in stable patients with ultrasonic features of high-risk plaques. Eur Heart J Cardiovasc Imaging 2014;15:1035-41.

28. Nicholls SJ, Hsu A, Wolski K, et al. Intravascular ultrasound-derived measures of coronary atherosclerotic plaque burden and clinical outcome. J Am Coll Cardiol 2010;5 5:2399-407.

29. Stone PH, Saito S, Takahashi S, et al. Prediction of progression of coronary artery disease and clinical outcomes using vascular profiling of endothelial shear stress and arterial plaque characteristics: the PREDICTION Study. Circulation 2012;126:172-81.

30. Neumann FJ, Sousa-Uva M, Ahlsson A, et al. 2018 ESC/ EACTS Guidelines on myocardial revascularization. Eur Heart J 2019;40:87-165.

31. Levine GN, Bates ER, Blankenship JC, et al. 2011 ACCF/AHA/SCAI Guideline for Percutaneous Coronary Intervention. A report of the American College of Cardiology Foundation/American Heart Association Task Force on Practice Guidelines and the Society for Cardiovascular Angiography and Interventions. J Am Coll Cardiol 2011;58:e44-122.

32. Budoff MJ, Shaw LJ, Liu ST, et al. Long-term prognosis associated with coronary calcification: observations from a registry of 25,253 patients. J Am Coll Cardiol 2007;49:1860-70.

33. Valenti V, Hartaigh BÓ, Heo R, et al. A 15-Year Warranty Period for Asymptomatic Individuals Without Coronary Artery Calcium: A Prospective Follow-Up of 9,715 Individuals. JACC Cardiovasc Imaging 2015;8:900-9.

34. Detrano R, Guerci AD, Carr JJ, et al. Coronary calcium as a predictor of coronary events in four racial or ethnic groups. N Engl J Med 2008;358:1336-45.

35. Criqui $\mathrm{MH}$, Denenberg JO, Ix JH, et al. Calcium density of coronary artery plaque and risk of incident cardiovascular events. JAMA 2014;311:271-8.
36. Budoff MJ, Young R, Burke G, et al. Ten-year association of coronary artery calcium with atherosclerotic cardiovascular disease (ASCVD) events: the multiethnic study of atherosclerosis (MESA). Eur Heart J 2018;39:2401-8.

37. McClelland RL, Jorgensen NW, Budoff M, et al. 10-Year Coronary Heart Disease Risk Prediction Using Coronary Artery Calcium and Traditional Risk Factors: Derivation in the MESA (Multi-Ethnic Study of Atherosclerosis) With Validation in the HNR (Heinz Nixdorf Recall) Study and the DHS (Dallas Heart Study). J Am Coll Cardiol 2015;66:1643-53.

38. Yeboah J, McClelland RL, Polonsky TS, et al. Comparison of novel risk markers for improvement in cardiovascular risk assessment in intermediate-risk individuals. JAMA 2012;308:788-95.

39. Silverman MG, Blaha MJ, Krumholz HM, et al. Impact of coronary artery calcium on coronary heart disease events in individuals at the extremes of traditional risk factor burden: the Multi-Ethnic Study of Atherosclerosis. Eur Heart J 2014;35:2232-41.

40. Grandhi GR, Mirbolouk M, Dardari ZA, et al. Interplay of Coronary Artery Calcium and Risk Factors for Predicting CVD/CHD Mortality: The CAC Consortium. JACC Cardiovasc Imaging 2020;13:1175-86.

41. Blaha MJ, Cainzos-Achirica M, Greenland P, et al. Role of Coronary Artery Calcium Score of Zero and Other Negative Risk Markers for Cardiovascular Disease: The Multi-Ethnic Study of Atherosclerosis (MESA). Circulation 2016;133:849-58.

42. Mortensen MB, Fuster V, Muntendam P, et al. Negative Risk Markers for Cardiovascular Events in the Elderly. J Am Coll Cardiol 2019;74:1-11.

43. Stone NJ, Robinson JG, Lichtenstein AH, et al. 2013 ACC/AHA guideline on the treatment of blood cholesterol to reduce atherosclerotic cardiovascular risk in adults: a report of the American College of Cardiology/American Heart Association Task Force on Practice Guidelines. J Am Coll Cardiol 2014;63:2889-934.

44. Nasir K, Bittencourt MS, Blaha MJ, et al. Implications of Coronary Artery Calcium Testing Among Statin Candidates According to American College of Cardiology/American Heart Association Cholesterol Management Guidelines: MESA (Multi-Ethnic Study of Atherosclerosis). J Am Coll Cardiol 2015;66:1657-68.

45. Catapano AL, Graham I, De Backer G, et al. 2016 ESC/ EAS Guidelines for the Management of Dyslipidaemias. Eur Heart J 2016;37:2999-3058. 
46. Bittencourt MS, Blankstein R, Blaha MJ, et al. Implications of coronary artery calcium testing on risk stratification for lipid-lowering therapy according to the 2016 European Society of Cardiology recommendations: The MESA study. Eur J Prev Cardiol 2018;25:1887-98.

47. Mitchell JD, Fergestrom N, Gage BF, et al. Impact of Statins on Cardiovascular Outcomes Following Coronary Artery Calcium Scoring. J Am Coll Cardiol 2018;72:3233-42.

48. Gupta A, Lau E, Varshney R, et al. The Identification of Calcified Coronary Plaque Is Associated With Initiation and Continuation of Pharmacological and Lifestyle Preventive Therapies: A Systematic Review and MetaAnalysis. JACC Cardiovasc Imaging 2017;10:833-42.

49. Arnett DK, Blumenthal RS, Albert MA, et al. 2019 ACC/AHA Guideline on the Primary Prevention of Cardiovascular Disease: A Report of the American College of Cardiology/American Heart Association Task Force on Clinical Practice Guidelines. J Am Coll Cardiol 2019;74:e177-e232.

50. Grundy SM, Stone NJ, Bailey AL, et al. 2018 AHA/ ACC/AACVPR/AAPA/ABC/ACPM/ADA/AGS/APhA/ ASPC/NLA/PCNA Guideline on the Management of Blood Cholesterol: A Report of the American College of Cardiology/American Heart Association Task Force on Clinical Practice Guidelines. J Am Coll Cardiol 2019;73:e285-e350.

51. Hecht HS, Cronin P, Blaha MJ, et al. 2016 SCCT/ STR guidelines for coronary artery calcium scoring of noncontrast noncardiac chest CT scans: A report of the Society of Cardiovascular Computed Tomography and Society of Thoracic Radiology. J Cardiovasc Comput Tomogr 2017;11:74-84.

52. Taylor AJ, Cerqueira M, Hodgson JM, et al. ACCF/SCCT/ ACR/AHA/ASE/ASNC/NASCI/SCAI/SCMR 2010 appropriate use criteria for cardiac computed tomography. A report of the American College of Cardiology Foundation Appropriate Use Criteria Task Force, the Society of Cardiovascular Computed Tomography, the American College of Radiology, the American Heart Association, the American Society of Echocardiography, the American Society of Nuclear Cardiology, the North American Society for Cardiovascular Imaging, the Society for Cardiovascular Angiography and Interventions, and the Society for Cardiovascular Magnetic Resonance. J Am Coll Cardiol 2010;56:1864-94.

53. Koo BK, Erglis A, Doh JH, et al. Diagnosis of ischemiacausing coronary stenoses by noninvasive fractional flow reserve computed from coronary computed tomographic angiograms. Results from the prospective multicenter DISCOVER-FLOW (Diagnosis of Ischemia-Causing Stenoses Obtained Via Noninvasive Fractional Flow Reserve) study. J Am Coll Cardiol 2011;58:1989-97.

54. Norgaard BL, Leipsic J, Gaur S, et al. Diagnostic performance of noninvasive fractional flow reserve derived from coronary computed tomography angiography in suspected coronary artery disease: the NXT trial (Analysis of Coronary Blood Flow Using CT Angiography: Next Steps). J Am Coll Cardiol 2014;63:1145-55.

55. Douglas PS, De Bruyne B, Pontone G, et al. 1-Year Outcomes of FFRCT-Guided Care in Patients With Suspected Coronary Disease: The PLATFORM Study. J Am Coll Cardiol 2016;68:435-45.

56. Rochitte CE, George RT, Chen MY, et al. Computed tomography angiography and perfusion to assess coronary artery stenosis causing perfusion defects by single photon emission computed tomography: the CORE320 study. Eur Heart J 2014;35:1120-30.

57. Cury RC, Abbara S, Achenbach S, et al. Coronary Artery Disease - Reporting and Data System (CAD-RADS): An Expert Consensus Document of SCCT, ACR and NASCI: Endorsed by the ACC. JACC Cardiovasc Imaging 2016;9:1099-113.

58. Meijboom WB, Meijs MF, Schuijf JD, et al. Diagnostic accuracy of 64-slice computed tomography coronary angiography: a prospective, multicenter, multivendor study. J Am Coll Cardiol 2008;52:2135-44.

59. Shaw LJ, Hausleiter J, Achenbach S, et al. Coronary computed tomographic angiography as a gatekeeper to invasive diagnostic and surgical procedures: results from the multicenter CONFIRM (Coronary CT Angiography Evaluation for Clinical Outcomes: an International Multicenter) registry. J Am Coll Cardiol 2012;60:2103-14.

60. Schulman-Marcus J, Hartaigh BO, Gransar H, et al. SexSpecific Associations Between Coronary Artery Plaque Extent and Risk of Major Adverse Cardiovascular Events: The CONFIRM Long-Term Registry. JACC Cardiovasc Imaging 2016;9:364-72.

61. Nielsen LH, Botker HE, Sorensen HT, et al. Prognostic assessment of stable coronary artery disease as determined by coronary computed tomography angiography: a Danish multicentre cohort study. Eur Heart J 2017;38:413-21.

62. Douglas PS, Hoffmann U, Patel MR, et al. Outcomes of anatomical versus functional testing for coronary artery disease. N Engl J Med 2015;372:1291-300.

63. SCOT-HEART Investigators. CT coronary angiography 
in patients with suspected angina due to coronary heart disease (SCOT-HEART): an open-label, parallel-group, multicentre trial. Lancet 2015;385:2383-91.

64. SCOT-HEART Investigators; Newby DE, Adamson PD, et al. Coronary CT Angiography and 5-Year Risk of Myocardial Infarction. N Engl J Med 2018;379:924-33.

65. Knuuti J, Wijns W, Saraste A, et al. 2019 ESC Guidelines for the diagnosis and management of chronic coronary syndromes. Eur Heart J 2020;41:407-77.

66. NICE. NICE guidance: Chest pain of recent onset: assessment and diagnosis. 2016. Available online: https:// www.nice.org.uk/guidance/cg95/evidence/full-guidelinepdf-245282221. Accessed 04.11.2019.

67. Motoyama S, Kondo T, Sarai M, et al. Multislice computed tomographic characteristics of coronary lesions in acute coronary syndromes. J Am Coll Cardiol 2007;50:319-26.

68. Puchner SB, Liu T, Mayrhofer T, et al. High-risk plaque detected on coronary CT angiography predicts acute coronary syndromes independent of significant stenosis in acute chest pain: results from the ROMICAT-II trial. J Am Coll Cardiol 2014;64:684-92.

69. Motoyama S, Sarai M, Harigaya H, et al. Computed tomographic angiography characteristics of atherosclerotic plaques subsequently resulting in acute coronary syndrome. J Am Coll Cardiol 2009;54:49-57.

70. Maurovich-Horvat P, Schlett CL, Alkadhi H, et al. The napkin-ring sign indicates advanced atherosclerotic lesions in coronary CT angiography. JACC Cardiovasc Imaging 2012;5:1243-52.

71. Obaid DR, Calvert PA, McNab D, et al. Identification of coronary plaque sub-types using virtual histology intravascular ultrasound is affected by inter-observer variability and differences in plaque definitions. Circ Cardiovasc Imaging 2012;5:86-93.

72. Voros S, Rinehart S, Qian Z, et al. Prospective validation of standardized, 3-dimensional, quantitative coronary computed tomographic plaque measurements using radiofrequency backscatter intravascular ultrasound as reference standard in intermediate coronary arterial lesions: results from the ATLANTA (assessment of tissue characteristics, lesion morphology, and hemodynamics by angiography with fractional flow reserve, intravascular ultrasound and virtual histology, and noninvasive computed tomography in atherosclerotic plaques) I study. JACC Cardiovasc Interv 2011;4:198-208.

73. Nakazato R, Otake H, Konishi A, et al. Atherosclerotic plaque characterization by CT angiography for identification of high-risk coronary artery lesions: a comparison to optical coherence tomography. Eur Heart J Cardiovasc Imaging 2015;16:373-9.

74. Motoyama S, Ito H, Sarai M, et al. Plaque Characterization by Coronary Computed Tomography Angiography and the Likelihood of Acute Coronary Events in Mid-Term Follow-Up. J Am Coll Cardiol 2015;66:337-46.

75. Feuchtner G, Kerber J, Burghard P, et al. The high-risk criteria low-attenuation plaque $<60 \mathrm{HU}$ and the napkinring sign are the most powerful predictors of MACE: a long-term follow-up study. Eur Heart J Cardiovasc Imaging 2017;18:772-9.

76. Williams MC, Moss AJ, Dweck M, et al. Coronary Artery Plaque Characteristics Associated With Adverse Outcomes in the SCOT-HEART Study. J Am Coll Cardiol 2019;73:291-301.

77. Lee SE, Sung JM, Andreini D, et al. Differences in Progression to Obstructive Lesions per High-Risk Plaque Features and Plaque Volumes With CCTA. JACC Cardiovasc Imaging 2020;13:1409-17.

78. Versteylen MO, Kietselaer BL, Dagnelie PC, et al. Additive value of semiautomated quantification of coronary artery disease using cardiac computed tomographic angiography to predict future acute coronary syndrome. J Am Coll Cardiol 2013;61:2296-305.

79. Diaz-Zamudio M, Dey D, Schuhbaeck A, et al. Automated Quantitative Plaque Burden from Coronary CT Angiography Noninvasively Predicts Hemodynamic Significance by using Fractional Flow Reserve in Intermediate Coronary Lesions. Radiology 2015;276:408-15.

80. Oikonomou EK, Marwan M, Desai MY, et al. Noninvasive detection of coronary inflammation using computed tomography and prediction of residual cardiovascular risk (the CRISP CT study): a posthoc analysis of prospective outcome data. Lancet 2018;392:929-39.

81. Oikonomou EK, Williams MC, Kotanidis CP, et al. A novel machine learning-derived radiotranscriptomic signature of perivascular fat improves cardiac risk prediction using coronary CT angiography. Eur Heart J 2019;40:3529-43.

82. Remonda L, Senn P, Barth A, et al. Contrast-enhanced 3D MR angiography of the carotid artery: comparison with conventional digital subtraction angiography. AJNR Am J Neuroradiol 2002;23:213-9.

83. Habibi R, Lell MM, Steiner R, et al. High-resolution 3T MR angiography of the carotid arteries: comparison of manual and semiautomated quantification of stenosis. 
AJNR Am J Neuroradiol 2009;30:46-52.

84. Mani V, Muntner P, Gidding SS, et al. Cardiovascular magnetic resonance parameters of atherosclerotic plaque burden improve discrimination of prior major adverse cardiovascular events. J Cardiovasc Magn Reson 2009;11:10.

85. Trivedi RA, Mallawarachi C, JM UK-I, et al. Identifying inflamed carotid plaques using in vivo USPIO-enhanced MR imaging to label plaque macrophages. Arterioscler Thromb Vasc Biol 2006;26:1601-6.

86. Smits LP, Tiessens F, Zheng KH, et al. Evaluation of ultrasmall superparamagnetic iron-oxide (USPIO) enhanced MRI with ferumoxytol to quantify arterial wall inflammation. Atherosclerosis 2017;263:211-8.

87. Yamada N, Higashi M, Otsubo R, et al. Association between signal hyperintensity on T1-weighted MR imaging of carotid plaques and ipsilateral ischemic events. AJNR Am J Neuroradiol 2007;28:287-92.

88. Sigovan M, Bidet C, Bros S, et al. 3D black blood MR angiography of the carotid arteries. A simple sequence for plaque hemorrhage and stenosis evaluation. Magn Reson Imaging 2017;42:95-100.

89. Alkhalil M, Biasiolli L, Chai JT, et al. Quantification of carotid plaque lipid content with magnetic resonance T2 mapping in patients undergoing carotid endarterectomy. PLoS One 2017;12:e0181668.

90. Chai JT, Biasiolli L, Li L, et al. Quantification of LipidRich Core in Carotid Atherosclerosis Using Magnetic Resonance T2 Mapping: Relation to Clinical Presentation. JACC Cardiovasc Imaging 2017;10:747-56.

91. Noguchi T, Yamada N, Higashi M, et al. High-intensity signals in carotid plaques on T1-weighted magnetic resonance imaging predict coronary events in patients with coronary artery disease. J Am Coll Cardiol 2011;58:416-22.

92. American College of Cardiology Foundation Task Force on Expert Consensus Documents; Hundley WG, Bluemke DA, et al. ACCF/ACR/AHA/NASCI/SCMR 2010 expert consensus document on cardiovascular magnetic resonance: a report of the American College of Cardiology Foundation Task Force on Expert Consensus Documents. J Am Coll Cardiol 2010;55:2614-62.

93. Dweck MR, Puntman V, Vesey AT, et al. MR Imaging of Coronary Arteries and Plaques. JACC Cardiovasc Imaging 2016;9:306-16.

94. Macedo R, Chen S, Lai S, et al. MRI detects increased coronary wall thickness in asymptomatic individuals: the multi-ethnic study of atherosclerosis (MESA). J Magn
Reson Imaging 2008;28:1108-15.

95. Kim WY, Stuber M, Bornert P, et al. Three-dimensional black-blood cardiac magnetic resonance coronary vessel wall imaging detects positive arterial remodeling in patients with nonsignificant coronary artery disease. Circulation 2002;106:296-9.

96. Noguchi T, Kawasaki T, Tanaka A, et al. High-intensity signals in coronary plaques on noncontrast T1-weighted magnetic resonance imaging as a novel determinant of coronary events. J Am Coll Cardiol 2014;63:989-99.

97. Asaumi Y, Noguchi T, Morita Y, et al. High-Intensity Plaques on Noncontrast T1-Weighted Imaging as a Predictor of Periprocedural Myocardial Injury. JACC Cardiovasc Imaging 2015;8:741-3.

98. Tang TY, Howarth SP, Miller SR, et al. The ATHEROMA (Atorvastatin Therapy: Effects on Reduction of Macrophage Activity) Study. Evaluation using ultrasmall superparamagnetic iron oxide-enhanced magnetic resonance imaging in carotid disease. J Am Coll Cardiol 2009;53:2039-50.

99. Rogers IS, Nasir K, Figueroa AL, et al. Feasibility of FDG imaging of the coronary arteries: comparison between acute coronary syndrome and stable angina. JACC Cardiovasc Imaging 2010;3:388-97.

100. Chowdhury MM, Tarkin JM, Evans NR, et al. (18)F-FDG Uptake on PET/CT in Symptomatic versus Asymptomatic Carotid Disease: a Meta-Analysis. Eur J Vasc Endovasc Surg 2018;56:172-9.

101. Chowdhury MM, Tarkin JM, Albaghdadi MS, et al. Vascular Positron Emission Tomography and Restenosis in Symptomatic Peripheral Arterial Disease: A Prospective Clinical Study. JACC Cardiovasc Imaging 2020;13:1008-17.

102. Tarkin JM, Joshi FR, Evans NR, et al. Detection of Atherosclerotic Inflammation by (68)Ga-DOTATATE PET Compared to [(18)F]FDG PET Imaging. J Am Coll Cardiol 2017;69:1774-91.

103. Tarkin JM, Calcagno C, Dweck MR, et al. (68)GaDOTATATE PET Identifies Residual Myocardial Inflammation and Bone Marrow Activation After Myocardial Infarction. J Am Coll Cardiol 2019;73:2489-91.

104. Dweck MR, Chow MW, Joshi NV, et al. Coronary arterial $18 \mathrm{~F}$-sodium fluoride uptake: a novel marker of plaque biology. J Am Coll Cardiol 2012;59:1539-48.

105. Joshi NV, Vesey AT, Williams MC, et al. 18F-fluoride positron emission tomography for identification of ruptured and high-risk coronary atherosclerotic plaques: a prospective clinical trial. Lancet 2014;383:705-13. 
106. Vesey AT, Jenkins WS, Irkle A, et al. (18)F-Fluoride and (18)F-Fluorodeoxyglucose Positron Emission Tomography After Transient Ischemic Attack or Minor Ischemic Stroke: Case-Control Study. Circ Cardiovasc Imaging 2017;10:e004976.

107.Fernandez-Friera L, Fuster V, Lopez-Melgar B, et al. Vascular Inflammation in Subclinical Atherosclerosis

Cite this article as: Kocyigit D, Scanameo A, Xu B. Multimodality imaging for the prevention of cardiovascular events: Coronary artery calcium and beyond. Cardiovasc Diagn Ther 2021;11(3):840-858. doi: 10.21037/cdt-19-654
Detected by Hybrid PET/MRI. J Am Coll Cardiol 2019;73:1371-82.

108. Seidelmann SB, Claggett B, Bravo PE, et al. Retinal Vessel Calibers in Predicting Long-Term Cardiovascular Outcomes: The Atherosclerosis Risk in Communities Study. Circulation 2016;134:1328-38. 